\title{
artigo
}

Rossone, F.O.; Oliveira, E.B.; Progianti, J.M.; Granadeiro, D.S.; Marques, F.C.; Souza, N.V.M.;

Precarização do trabalho em hospital universitário: contribuições de um serviço de saúde do trabalhador

\section{Precarização do trabalho em hospital universitário: contribuições de um serviço de saúde do trabalhador}

\begin{abstract}
RESUMO
Objetivos: analisar os fatores que contribuíram para a precarização do trabalho em hospital universitário e discutir as implicações para a saúde dos trabalhadores de enfermagem sob a ótica de um serviço de saúde ocupacional. Métodos: estudo qualitativo, descritivo que teve como campo um Serviço de Saúde do Trabalhador de um hospital universitário. Utilizou-se a técnica de entrevista mediante um roteiro com 14 trabalhadores e na categorização dos depoimentos aplicou-se a análise de conteúdo temática. Resultados: a precarização do trabalho na instituição ocorreu em função da ausência de concurso público; a necessidade de profissionais para a continuidade de serviços essenciais; e a redução de gastos com pessoal. A instabilidade do vínculo empregatício acarreta nos trabalhadores temporários quadros de estresse, ansiedade, reações depressivas e impotência. Conclusão: há necessidade de promoção da saúde dos trabalhadores mediante política institucional que garanta a estabilidade dos vínculos empregatícios e os direitos trabalhistas previstos em lei.
\end{abstract}

DESCRITORES: Enfermagem; Recursos Humanos em Saúde; Saúde do Trabalhador.

\section{ABSTRACT}

Objectives: analyze the factors that contributed to the precariousness of work in a university hospital and discuss the health implications of nursing workers from the perspective of an occupational health service. Methods: a qualitative, descriptive study that had as field an Occupational Health Service of a university hospital. The interview technique was used through a script with 14 workers and in the categorization of the statements applied thematic content analysis. Results: the precariousness of the work in the institution was due to the absence of public politic, the urgency of professionals for the continuity of essential services and reduction of personnel expenses. The instability of the employment link causes temporary workers stress, anxiety, depression and feelings of helplessness. Conclusion: there is a need to promote workers' health through an institutional policy that guarantees the stability of employment relationships and the labor rights provided for by law.

KEYWORDS: Nursing; Human Resources in Health; Worker's Health.

\section{RESUMEN}

Objetivos: analizar los factores que contribuyeron a la precariedad del trabajo en un hospital universitario y discutir las implicaciones para la salud de los trabajadores de enfermería desde la perspectiva de un servicio de salud ocupacional. Métodos: estudio cualitativo y descriptivo que tuvo como campo un Servicio de Salud Ocupacional de un hospital universitario. La técnica de la entrevista se utilizó a través de un guión con 14 trabajadores y la categorización de las declaraciones aplicó análisis de contenido temático. Resultados: en opinión de los participantes, la precariedad del trabajo en la institución se debió a la ausencia de licitación pública, la urgencia de los profesionales para la continuidad de los servicios esenciales y la reducción de los gastos de personal. La inestabilidad del vínculo laboral causa estrés, ansiedad, depresión y sentimientos de impotencia a los trabajadores temporales. Conclusión: es necesario promover la salud de los trabajadores a través de una política institucional que garantice la estabilidad de las relaciones laborales y los derechos laborales previstos por la ley.

PALABRAS CLAVE: Enfermería; Recursos Humanos en Salud; Salud del Trabajador.

RECEBIDO EM: 23/08/2019 APROVADO EM: 23/08/2019

\section{Felipe Oliveira Rossone}

Enfermeiro. Mestre em Enfermagem. Especialista em Enfermagem do Trabalho. Secretaria de Saúde do Estado do Rio de Janeiro (SSE/RJ).

\section{Elias Barbosa de Oliveira}

Enfermeiro. Doutor em Enfermagem. Professor Associado do Departamento de Enfermagem Médico Cirúrgico da Universidade do Estado do Rio de Janeiro. 


\section{Jane Marcia Progianti}

Enfermeira. Doutora em Enfermagem. Professora Titular do Departamento de Enfermagem Materno Infantil da Universidade do Estado do Rio de Janeiro.

\section{Daniel da Silva Granadeiro}

Enfermeiro. Mestre em Enfermagem. Professor Assistente. Centro Universitário Augusto Mota (UNISUAM). Rio de Janeiro (RJ).

\section{Fernanda Chagas Marques}

Enfermeira. Especialista em Auditoria e Gestão em Saúde. Mestranda em Enfermagem, Programa de Pós Graduação em Enfermagem da Universidade do Estado do Rio de Janeiro.

\section{Natalia Victor Madeira de Souza}

Enfermeira. Especialista em Enfermagem do Trabalho. Mestranda em Enfermagem, Programa de Pós Graduação em Enfermagem da Universidade do Estado do Rio de Janeiro.

\section{INTRODUÇÃO}

0 serviço de saúde do trabalhador visa, sobretudo, a qualidade de vida dos profissionais, a prevenção de acidentes e danos à saúde advindos ou relacionados ao trabalho ou que ocorram no curso dele, mediante ações de vigilância epidemiológica e sanitária de alcance individual e coletivo dos trabalhadores expostos a riscos e agravos a saúde ${ }^{(1)}$. No entanto, as ações dirigidas à saúde do trabalhador vêm sendo prejudicadas em função do modelo neoliberal vigente em que se observa a precarização do trabalho, com prejuízos da cultura organizacional, os projetos de trabalho em médio e longo prazos e a continuidade das políticas e programas em saúde do trabalhador ${ }^{(2)}$.

$\mathrm{O}$ atendimento em saúde do trabalhador, que deveria ser igualitário e de acesso a todos profissionais, vem sendo prejudicado em função da política recessiva disseminada pelo Estado a partir da década de 1990, que se legitimou através da Reforma Administrativa (Emenda Constitucional n. ${ }^{\circ}$ 19/98). A partir de então, as instituições públicas passaram a adotar múltiplas formas de vínculos trabalhistas, que incluem: o regime estatutário, o celetista, terceirizado e temporário ou precário ${ }^{(3,4)}$. Neste contexto, observa-se a diminuição de trabalhadores concursados e a substituição através da terceirização e precarização, tendo como consequências: quebra de direitos trabalhistas, menores salários e submissão dos profissionais a condições de trabalho inadequadas com riscos de acidentes e doenças ocupacionais ${ }^{(5)}$.

A precarização vem incidindo de modo marcante na saúde mental dos trabalhadores e na organização do trabalho acrescida das limitações impostas em muitas empresas ao bom funcionamento dos Serviços de Engenharia de Segurança e Medicina do Trabalho (SESMT) no país, em nome da equivocada contenção de custos. Há problemas relativos às defasagens de treinamento $\mathrm{e}$ de informações sobre os riscos ocupacionais, diluição das responsabilidades em relação a acidentes, adoecimentos e falhas na prevenção relativos à saúde do trabalhador ${ }^{(6)}$.

A partir do exposto, elaborou-se as seguintes questóes norteadoras: Quais os fatores que contribuíram para a precarização do trabalho em hospital universitário sob a ótica de um serviço de saúde ocupacional? Quais as implicações da precarização do trabalho em hospital universitário para a saúde dos trabalhadores de enfermagem na visão de um serviço de saúde ocupacional? No intuito de responder a essas questões, o presente estudo possui como objetivos analisar os fatores que contribuíram para a precarização do trabalho em um hospital universitário e discutir as implicações para a saúde dos trabalhadores de enfermagem sob a ótica de um serviço de saúde ocupacional.

\section{METODOLOGIA}

Estudo descritivo com abordagem qualitativa, cujo campo foi um Serviço de Saúde do Trabalhador (SST) de um hospital universitário localizado no município do Rio de Janeiro. O projeto atendeu às normas éticas em pesquisa envolvendo seres humanos, sendo aprovado pelo Comitê de Ética em Pesquisa do Hospital Universitário Pedro Ernesto da Universidade do Estado do Rio de Janeiro (CEP/HUPE/ UERJ), Parecer n. ${ }^{\circ}$ 1.436.320. Em atendimento à Resolução n. $.^{\circ} 466 / 12$ do Conselho Nacional de Saúde (CNS), após a assinatura no Termo de Consentimento Livre e Esclarecido (TCLE), participaram do estudo 14 trabalhadores (03 enfermeiros, 04 médicos e 07 técnicos de enfermagem).

Os critérios adotados na seleção dos participantes do estudo foram: profissionais de nível superior e/ou médio, estatutários e que estivessem exercendo as suas atividades no SST pelo menos há três anos, tempo necessário ao considerar o processo de precarização do trabalho que vinha ocorrendo há alguns anos na instituição. Excluídas do estudo duas técnicas de enfermagem que se encontravam afastadas devido à licença médica e maternidade.

O serviço de saúde do ocupacional localiza-se no próprio hospital, sendo constituído pelas seguintes áreas: recepção, consultórios médicos e de enfermagem, sala de realização de alguns testes, copa, banheiro e sala de reuniões. $\mathrm{O}$ serviço funciona de 8 às 17 horas. Além do atendimento aos servidores do hospital, os profissionais realizam vigilância em atenção às normas técnicas adotadas, palestras, participação em campanhas de imunização, confecção do mapa de risco, acompanhamento do trabalhador no caso de acidentes de trabalho, dentre outras 
atividades. A equipe é composta por 03 enfermeiros, 04 médicos e 09 técnicos de enfermagem, sendo todos estatutários e com mais de cinco anos de experiência.

A coleta de dados foi realizada no primeiro trimestre de 2016, em que se adotou a técnica de entrevista mediante um instrumento estruturado para a caracterização sociodemográfica e laboral dos participantes e um roteiro confeccionado pelo pesquisador contendo perguntas abertas acerca da precarização do trabalho. As entrevistas foram registradas em meio digital, realizadas no próprio serviço em local privativo, após agendamento e explicações acerca dos objetivos e demais aspectos éticos.

Informou-se que a participação seria voluntária e garantiu-se o direito de o entrevistado retirar o consentimento do estudo em qualquer fase, sem que isso trouxesse qualquer dano ou retaliação. Ratificou-se que os resultados seriam apresentados em eventos e publicados em revistas científicas. No intuito de manter o anonimato dos entrevistados, adotou-se as seguintes convenções: letra E (Entrevistado) seguido da abreviatura da categoria profissional (E=Enfermeiro; $\mathrm{M}=$ Médico e TE=Técnico de Enfermagem) e de um numeral de acordo com a ordem de realização das entrevistas (EE1, EM2, ETE3...).

Os depoimentos foram analisados mediante a técnica de análise de conteúdo do tipo temática que se baseou na decodificação do texto em diversos elementos, os quais foram classificados e formaram agrupamentos analógicos ${ }^{(7)}$. Após a transcrição das entrevistas na íntegra, foram extraídas as unidades de registro e, a seguir, agrupadas em unidades temáticas de acordo com os critérios de homogeneidade, representatividade e exaustividade.

Em um último momento, utilizando os critérios de reclassificação e agregação dos elementos do conjunto, elaborou-se as seguintes categorias: Contensão de gastos e vínculos instáveis e Desproteção social no trabalho: saúde em risco. A seguir são apresentados os resultados referentes às características dos participantes e as categorias empíricas do estudo.

\section{RESULTADOS}

\section{Características dos participantes}

Participaram do estudo 14 trabalhadores da área técnica do Serviço de Saúde do Trabalhador de um hospital de ensino, a partir dos critérios de inclusão estabelecidos. São do sexo feminino $(64,3 \%)$ e masculino $(36 \%)$, casados $(42,9 \%)$, faixa etária acima de 42 anos $(71,4 \%)$. Todos eram estatutários, atuavam no SST há mais de 3 anos; portanto, um grupo bastante experiente acerca dos problemas relacionados ao processo de precarização que a instituição hospitalar vinha passando. Cumpriam carga horária semanal de 30 horas (57,2\%), formados há mais de 12 anos (85,75\%) em nível de Graduação (57,2\%), especialistas na Área de Saúde do Trabalhador e/ou afins (50\%) e nível médio (28,6\%).

\section{Contensão de encargos financeiros e vínculos instáveis}

$\mathrm{Na}$ visão dos participantes, a ausência de concurso público para suprir a necessidade de pessoal no hospital foi o principal fator que impulsionou a contratação de trabalhadores temporários como estratégia de manutenção de serviços essenciais operantes. Por se tratar de uma instituição universitária, deve-se considerar o impacto ocasionado pela insuficiência de recursos humanos nos diversos centros que se dedicam à pesquisa, ao ensino e à assistência e, dentre eles, o hospitalar que para atender as demandas de cunho técnico e assistencial, necessita de pessoal em termos quantitativos e qualitativos, como referido:

"não abriu concurso por um longo periodo! Nós tivemos vários contratos passando aqui, mas nenhum concurso. A gente percebe que as contrataçôes são mais rápidas de se conseguir! E a demanda era urgente" (EM14).

"O problema principal é a falta dos concursos públicos! Além da facilidade em se contratar profissionais temporários! Os concursos estão escassos e a necessidade de pessoal existe! Então isso acaba justificando esse tipo de contrato" (ET1).
"Sem concurso, você não repóe pessoal! A demanda (referindo-se aos serviços) só aumenta e o número de profissionais diminui! Isso já é motivo suficiente para colocarem pessoal temporário"(EE5).

Além da ausência de concurso público para suprir a necessidade de pessoal, a precarização do trabalho ocorrida na instituição, sob o ponto de vista dos entrevistados, teve como fator determinante a crise financeira do Estado e a contensão de custos; fatores que afetaram diretamente a disponibilidade de recursos humanos para a continuidade de prestação de serviços essenciais, como relatado:

"Para o governo é mais lucrativo ter
profissionais contratados tempora-
riamente! Que não possuem seus di-
reitos garantidos e por ser mais bara-
to do que contratar servidor público"
(ET9).

"É mais barato com relação a concurso! A realização do contrato é mais barata do que realizar um concurso. Eu gostaria que a remuneração fosse igual, mas realmente o contrato tem uma diferença salarial. A estratégia de gestão de redução do quadro fixo e de precarização das relações de trabalho torna isso mais barato" (EE5).

\section{Desproteção social no trabalho: saú- de em risco}

A precarização do trabalho por não garantir aos profissionais temporários os direitos trabalhistas previstos em lei contribui para a instabilidade empregatícia e desproteção social dos trabalhadores de enfermagem, marcada por sentimento de insegurança e medo do desemprego frente a um futuro incerto. Esta situação de trabalho promove um clima organizacional desfavorável ao bem-estar e a saúde dos trabalhadores, como evidenciado nos depoimentos:

"A precarização cria essa instabilidade! E essa instabilidade afeta qualquer trabalhador; seja o trabalhador temporário aqui ou em 
qualquer outro lugar! Se ele tem emprego hoje e não tem amanhã vai deixá-lo desestabilizado" (EM11).

"Existe uma insegurança tão grande que o indivíduo vai pra casa sem saber se na volta ele estará trabalhando ou não! Se ele vai chegar e assinar a carta de demissão! Se ele ainda faz parte do quadro de pessoal ou não" (ET4).

"Há a ansiedade só pelo fato de não ter garantias, não ter motivação para continuar ali, somado ao estresse que já existe e todos os problemas que esse estresse traz para 0 ser humano! Irritabilidade, fadiga, depressão, medo, até mesmo transtornos graves" (EE10).

\section{DISCUSSÃO}

No serviço público brasileiro, a precarização crescente das relações de trabalho refere-se ao não preenchimento de vagas ociosas dos trabalhadores que deixam a instituição, ou se aposentam, e à expansão crescente do processo de terceirização através das Organizações Sociais. Os contratos temporários em tempo parcial (horistas) e a quebra de vínculos oriundos da gestão privada são amplamente disseminados na esfera pública, corroem as equipes de trabalho, geram insegurança e sobrecarga de trabalho(4). Os hospitais universitários como parte da rede assistencial em saúde no país, amparados na emenda da reforma administrativa, passaram a adotar em seu quadro de pessoal vínculos estatutário, celetista e precário, caracterizando a flexibilização do trabalho devido as mudanças relativas ao regime jurídico único e a modificação das regras sobre a estabilidade no cargo público ${ }^{(6,8)}$.

Acompanhando a concepção de um processo de trabalho flexível, o mercado se configura com a livre contratação e negociação, através da flexibilização da jornada de trabalho, da remuneração e dos direitos sociais. Neste contexto, apesar de fenômenos distintos, o neoliberalismo, a globalização e a reestruturação produtiva estão articulados com as transformações que vêm acontecendo no capitalismo das últimas décadas. Tais fenômenos compartilham do ideal de flexibilização nos diversos setores da sociedade e com reflexos importantes no setor saúde e na enfermagem, no qual a reestruturação produtiva encontra-se presente, tanto na perspectiva da gestão do sistema de saúde, quanto na organização do processo de trabalho ${ }^{(9)}$.

$\mathrm{Na}$ enfermagem, apesar de o vínculo empregatício estatutário congregar o maior número de trabalhadores, houve um crescimento de contratos terceirizados e temporários nas três esferas do governo em função do modelo neoliberal e a flexibilização das relações trabalhistas. Trata-se de uma profissão com forte inserção nas estruturas formais de emprego, o que reforça a ideia de que a empregabilidade é uma questão central, podendo-se afirmar que há indícios de desemprego e subemprego na categoria. Há um alto índice de profissionais que possui somente um emprego, sendo o hospital o principal locus de trabalho da categoria, apesar de desgastante e exaustivo ${ }^{(10,11)}$.

Sob o ponto de vista econômico, a precarização mostra-se mais lucrativa para o empregador que busca associar diminuição de custos com alta lucratividade, tendo como consequência a terceirização da produção e a redução dos encargos advindos da abertura de concursos, realização de treinamentos e cumprimento das obrigações previdenciárias e/ou trabalhistas. Dessa forma, torna-se menos oneroso para as empresas recorrerem a uma força de trabalho fragilizada em um contexto de flexibilização, na qual a relação trabalhista, geralmente, se dá mediante ausência de proteção social ${ }^{(12)}$.

A Enfermagem é uma força de trabalho que vem sendo onerada em função dos novos modelos produtivos cujos princípios estão ancorados na minimização de gastos e maximização de lucro/produtividade. Deste modo, reduz-se o quadro de pessoal efetivo e contrata-se pessoal com vínculo precário, acarretando elevada rotatividade e fuga de capital intelectual. Como consequências, há necessidade de recrutamento, seleção e treinamento constantes, de modo que os recém-contratados se familiarizem com a dinâmica do trabalho e mantenham a qualidade do atendimento ${ }^{(13)}$.

A precarização do trabalho nas instituições de saúde se expressa no controle maximizado através da gestão pelo medo, das práticas participativas forçadas, da imposição da intensificação do trabalho e da polivalência. Os processos de dominação mesclam insegurança, sequestro do tempo e da subjetividade dos indivíduos, afetando as demais dimensões da vida social e familiar. Produz-se assim, a desestabilização do mundo do trabalho com aniquilação da sua regulação social e a construção social de um trabalho socialmente desagregador; terreno fértil para o sofrimento e o adoecimento dos indivíduos, configurando o trabalho patogênico ${ }^{(4)}$.

A flexibilização e consequente diferenças de vínculos empregatícios promovem conflitos entre trabalhadores e a perda da memória institucional pela falta de fixação dos profissionais temporários. Há a desorganização dos processos de trabalho, desestruturação dos serviços, descontinuidade das ações de saúde, insatisfação, desmotivação e insegurança dos trabalhadores temporários que não se sentem parte do coletivo. A adoção de vários tipos de arranjos contratuais não garante as necessidades de proteção social dos trabalhadores, conforme estabelecido nas normas do Direito Trabalhista Brasileiro, que visam a defesa do trabalhador, haja vista ser este o elo mais fraco da relação trabalhista e, logo, necessitando de proteção maior ${ }^{(6)}$.

Um dos aspectos relevantes no que se refere à proteção social do trabalhador é a garantia de afastamento do trabalho para tratamento de problemas de saúde. No entanto, com a precarização, os trabalhadores de enfermagem por se sentirem desprotegidos socialmente, evitam faltar ao trabalho e/ou se afastar dos postos de trabalho para cuidar da própria saúde, comparecendo ao serviço mesmo com doenças agudas ou crônicas, caracterizando assim o presenteísmo. Constrangido pelas normas estabelecidas, o trabalhador presenteísta além de ter o seu desempenho afetado sobrecarrega as equipes, pois o não afastamento impede a sua substituiçãõo ${ }^{(14)}$.

Nos novos modelos produtivos do tra- 


\section{artigo}

Rossone, F.O.; Oliveira, E.B.; Progianti, J.M.; Granadeiro, D.S.; Marques, F.C.; Souza, N.V.M.

balho em saúde, a insuficiência de recursos humanos em termos quantitativos e qualitativos repercute no processo de trabalho da enfermagem, tendo como consequência prejuízos para a saúde física e mental dos profissionais, evidenciando-se estresse e sentimentos como angústia, frustração, tristeza e insatisfação. Acrescenta-se que o profissional, em muitas ocasiões, realiza o trabalho em ambientes penosos ou inadequados devido ao não cumprimento das normas regulamentadoras, expondo-se a riscos de acidentes e adoecimento pelo excesso de horas trabalhadas ${ }^{(15)}$.

Considerando-se a relevância social do trabalho de enfermagem, ratifica-se a importância de um ambiente organizacional que proporcione aos profissionais uma prática com autonomia, controle sobre o ambiente físico e social do trabalho e pautada no bom relacionamento interpessoal entre os componentes da equipe e demais profissionais. Tais fatores, além de contribuírem para a saúde mental e minimizarem o desgaste, são relevantes no que dizem respeito à satisfação no trabalho e à prestação de cuidados seguros.

\section{CONCLUSÃO}

$\mathrm{Na}$ visão dos participantes, os fatores que contribuíram para a precarização do trabalho na instituição foram a ausência de concurso público para suprir a necessidade de pessoal e a contensão de custos com pessoal, sendo a contratação de trabalhadores temporários mais lucrativa para a institui- ção por diminuir os encargos financeiros com a realização de concurso público, o pagamento de salários condizentes com a função e o não cumprimento das obrigações trabalhistas previstas na Consolidação das Leis Trabalhistas.

Como consequências deste tipo de gestão, há repercussões para a saúde dos trabalhadores de enfermagem, principalmente os temporários, devido à instabilidade empregatícia, à ausência de direitos trabalhistas e à desproteção social. Há necessidade de uma politica institucional com vistas à realização de concurso público que garanta a estabilidade no emprego, os direitos trabalhistas e a saúde ocupacional; o que requer mobilização dos trabalhadores e a organização do trabalho.

\section{REFERÊNCIAS}

1. Gomez CM, Vasconcelos CF, Machado JMH. A brief history of worker's health Brazil's Unified Health System: progress and challenges. Ciênc. Saúde Coletiva [Internet]. 2018 [acesso em 23 ago 2019]; 23(6):11-30. DOI: https://doi.org/10.1590/141381232018236.04922018.

2.Paim JS. Thirtyyears of theUnified Health System(SUS). CiêncSaúde Coletiva [Internet]. 2018 [acesso em 23 ago 2019]; 23(6):17268. DOI: http:/dx. doi: 10.1590/1413-81232018236.09172018.

3. Albuquerque MSV, Morais HMM, Lima LP. The contracting process and outsourcing in health: the scenario for dispute between public and private. Ciênc Saúde Coletiva [Internet]. 2015 [acesso em 23 ago 2019]; 20(6):1825-34. DOl: http://dx.doi. org/10.1590/1413-81232015206.11862014.

4. Druck G. The outsourcing in public health: various forms of precarization of labor. Trab Educ Saúde [Internet] 2016 [acesso em 23 ago 2019]; 14(supp1):15-43. Disponivel em: http://www.scielo.br/scielo.php?script=sci_arttext\&pid=S1981-77462016000400015\&Ing=en\&nrm=iso\&tlng=pt.

5.Pialarissi R. Precarização do trabalho. Rev Adm Saúde [Internet]. 2017 [acesso em 23 ago 2019]; 17(66). Disponivel em: http:// www.cqh.org.br/ojs-2.4.8/index.php/ras/article/view/11/21.

6. Souza HS, Mendes AN. Outsourcing and dismantling of steady jobs at hospital. Rev Esc Enferm USP [Internet]. 2016 [acesso em 23 ago 2019]; 50(2):284-91. DOl: http://dx.doi.org/10.1590/ S0080-623420160000200015.

7. Bardin L. Análise de conteúdo. Lisboa (Pt): Edições 70; 2011.

8. Alves MP, Coelho MCR, Borges LH, Cruz CAM, Massaroni L, Maciel PMA. The flexibilization of employment relationships in the health sector: the reality in a Federal University Hospital in Brazil. Ciênc Saúde Coletiva [Internet]. 2015 [acesso em 23 ago 2019]; 20:3043-50. DOl: http://dx.doi.org/10.1590/1413812320152010.11592014.
9. Machado MH, Oliveira E, Lemos W, Lacerda WF, Filho Wilson A, Wermelinger $\mathbf{M}$, et al. Mercado de trabalho da enfermagem: aspectos gerais. Enferm Foco [Internet]. 2016 [acesso em 23 ago 2019] 7(esp):35-62. Disponivel em: http://revista.portalcofen. gov.br/index.php/enfermagem/article/view/691/301.

10. Ribeiro AC, Souza JF, Silva JL. Lack of employment security in the sus in the perspective of hospital nursing. Cogitare Enferm [Internet]. 2014 [acesso em 23 ago 2019]; 19:569-75. DOl: http:// dx.doi.org/10.5380/ce.v19i3.33034.

11. Medeiros FMMA, Lins MAT, Ferreira NTG, Silva PAS. As relações de trabalho na contemporaneidade brasileira. Caderno de Graduação-Ciências Humanas e Sociais-FITS [Internet]. 2013 [acesso em 23 ago 2019]; 1(2):47-9. Disponivel em: https://periodicos.set.edu.br/index.php/fitshumanas/article/view/700/381.

12. Souza NVDO, Gonçalves FGA, Pires AS, David HMS. Neoliberalist influences on nursing hospital work process and organization. Rev. Bras. Enferm [Internet]. 2017 [acesso em 23 ago 2019]; 70(5): 912-19. DOI: http:/dx.doi.org/10.1590/0034-7167-2016-0092.

13. Vieira MLC, Oliveira EB, Souza NVDO, Lisboa MTL, Xavier T, Rossone FO. Job insecurity at a teaching hospital and presenteeism among nurses. Rev. enferm UER] [Internet]. 2016 [acesso em 23 ago 2019]; 24(4):e23580. DOl: http://dx.doi.org/10.12957/ reuerj.2016.23580.

14. Gonçalves FGA, Souza NVDO, Zeitoune RCG, Adame GFP, Nascimento SMP. Impacts of neoliberalism on hospital nursing work. Text Contexto Enferm [Internet]. 2015 [acesso em 23 ago 2019]; 24(3):646-3. DOl: http://dx.doi.org/10.1590/010407072015000420014.

15. Gasparino RC, Guirardello EB. Professional practice environment and burnout among nurses. Rev Rene [Internet]. 2017 [acesso em 23 ago 2019]; 16(1):90-6. DOl: http://dx.doi: $10.15253 / 2175-6783.2015000100012$. 